\title{
Porewater exchange and the saltmarsh carbon pump: Implications for blue carbon budgets
}

\section{XIAOGANG CHEN}

Westlake University

Presenting Author: chenxiaogang@westlake.edu.cn

Saltmarshes sequester large amounts of carbon in soils but limited information is available on carbon losses. Here, we conducted field observations under different seasonal and tidal conditions to quantify the carbon pathways via porewater exchange, outwelling and outgassing in a Chinese saltmarsh creek. ${ }^{222} \mathrm{Rn}$-derived porewater exchange rates were 11.1-36.6 $(16.3 \pm 5.1) \mathrm{cm} \mathrm{day}^{-1}$, which released 1.7 times more carbon in the wet season than in the dry season. These carbon flows are mainly DOC (>70\%) rather than DIC and greenhouse gases. Seasonal and tidal carbon dynamics were displayed in the creek waters. Counterintuitively, in the wet season, the porewater exchange rates and related carbon fluxes during the spring tide were lower than those during the neap tide. This is because, in addition to crab burrow flushing (i.e., semi-diurnal timescale), surface water in the higher intertidal zone infiltrates into the sediments during the spring tide, and seeps into the creek as tidal amplitude decreases (i.e., spring-neap timescale). DIC outwelling was the largest outwelling contributor. Water-atmosphere $\mathrm{CO}_{2}$ and $\mathrm{CH}_{4}$ emissions were 93-242 and 0.17-0.39 $\mathrm{mmol} \mathrm{m}^{-2}$ day ${ }^{-1}$, respectively. The saltmarsh carbon budgets we estimated imply that the porewater-derived carbon and carbon outwelling were approximately 1.3 times and $22 \%$ of carbon burial, respectively. Therefore, porewater exchange and outwelling should be considered in the assessment of the blue carbon paradigm and its role in mitigating climate change. 